\title{
Predictors, Risk Factors, and Incidence Rates of Psoriatic Arthritis Development in Psoriasis Patients: A Systematic Literature Review and Meta- Analysis
}

\author{
Alen Zabotti (1) - Orazio De Lucia · Garifallia Sakellariou • Alberto Batticciotto · Gilberto Cincinelli • \\ Ivan Giovannini · Luca Idolazzi · Gabriella Maioli · Ilaria Tinazzi · Daniel Aletaha · Salvatore De Vita • \\ Antonio Marchesoni $\cdot$ Josef Smolen $\cdot$ Annamaria Iagnocco $\cdot$ Dennis McGonagle $\cdot$ Roberto Caporali
}

Received: August 17, 2021 / Accepted: September 16, 2021 / Published online: October 1, 2021

(C) The Author(s) 2021

\section{ABSTRACT}

Background: Agreement on how to identify psoriasis (PsO) patients at risk of developing psoriatic arthritis (PsA) is lacking.

Objective: To identify predictors, risk factors and incidence rate (IR) of PsA development in $\mathrm{PsO}$ patients through a systematic literature review (SLR) and meta-analyses (MA).

Supplementary Information The online version contains supplementary material available at https:// doi.org/10.1007/s40744-021-00378-w.

A. Zabotti · I. Giovannini · S. De Vita

Department of Medical and Biological Science, Rheumatology Clinic, University of Udine, Udine, Italy

O. De Lucia · G. Cincinelli · G. Maioli ·

A. Marchesoni · R. Caporali

Department of Rheumatology and Medical Sciences,

ASST Centro Traumatologico Ortopedico G. Pini-

CTO, Milan, Italy

G. Sakellariou

Division of Rheumatology, University of Pavia,

Istituti Clinici Scientifici Maugeri, Pavia, Italy

A. Batticciotto

Rheumatology Unit, Department of Internal

Medicine, ASST-Settelaghi. "Ospedale di Circolo-

Fondazione Macchi", Varese, Italy

L. Idolazzi

Rheumatology Unit, University of Verona, Ospedale

Civile Maggiore, Verona, Italy
Methods: MEDLINE, Embase, and Cochrane databases were searched. Cohort studies were used to assess the predictors, while case-control studies for PsA risk factor determination.

Results: We screened 4698 articles for eligibility, and 110 underwent a full reading and 26 were finally included. Among skin and nail phenotypes, PsO severity and nail pitting were selected as predictors of PsA development. Furthermore, PsO patients with arthralgia (pooled RR 2.15 [1.16; 3.99]) and/or with imaging-MSK inflammation (pooled RR 3.72 [2.12; 6.51]) were at high risk of PsA. Higher categories of BMI and a family history of PsA were other predictors. In

I. Tinazzi

Unit of Rheumatology, Negrar, IRCSS Ospedale Sacro Cuore Don Calabria, Verona, Italy

D. Aletaha $\cdot$ J. Smolen

Division of Rheumatology, Department of Medicine 3, Medical University of Vienna, Wien, Austria

\section{A. Iagnocco}

Dipartimento di Scienze Cliniche e Biologiche, Academic Rheumatology Centre, Università degli Studi di Torino, Torino, Italy

D. McGonagle

Leeds Institute of Rheumatic and Musculoskeletal Medicine (LIRMM), University of Leeds, Leeds, UK
A. Zabotti $(\bowtie)$
Department of Specialist Medicine, Rheumatology
Clinic, Azienda Sanitaria Universitaria Friuli
Centrale, Piazzale S. Maria della Misericordia, 15, 33100 Udine, Italy
e-mail: zabottialen@gmail.com 
outpatient-based cohort studies, the IR of PsA per 100 patient-years varied from 1.34 to 17.4 .

Limitations: Despite the strength of the overall results, the heterogeneity and the number of the cohort studies could be considered a limitation.

Conclusions: This study provides a tentative profile of the PsO patient at risk of PsA and will help the design of PsA prevention trials.

Keywords: Psoriasis; Psoriatic arthritis; Systematic review; Early psoriatic arthritis; Disease interception; Disease prevention

\begin{tabular}{|c|c|}
\hline \multicolumn{2}{|c|}{ Abbreviations } \\
\hline BMI & Body mass index \\
\hline CASPAR & $\begin{array}{l}\text { Classification criteria for psoriatic } \\
\text { arthritis }\end{array}$ \\
\hline HR & Hazzard ratio \\
\hline HR-pQCT & $\begin{array}{l}\text { High-resolution } \\
\text { quantitative } \\
\text { tomography }\end{array}$ \\
\hline IR & Incidence rate \\
\hline MA & Meta-analysis \\
\hline MOOSE & $\begin{array}{l}\text { Meta-analysis Of Observational } \\
\text { Studies in Epidemiology }\end{array}$ \\
\hline MRI & Magnetic resonance imaging \\
\hline MSK & Musculoskeletal \\
\hline MSK-US & Musculoskeletal ultrasound \\
\hline NOS & Newcastle Ottawa Scale \\
\hline PASI & Psoriasis Area Severity Index \\
\hline PsA & Psoriatic arthritis \\
\hline $\mathrm{PsO}$ & Psoriasis \\
\hline RR & Relative risk \\
\hline SRL & Systematic literature review \\
\hline
\end{tabular}

\section{Key Summary Points}

Identifying PsO patients at increased risk for transition to PsA is challenging.

This SRL provides a synthesis of predictors and risk factors of PsA development in PsO patients.

These results are crucial for the characterization of the preclinical phases of PsA and for the design of prevention and interception trials.

\section{INTRODUCTION}

Psoriatic arthritis (PsA) manifests clinically in several ways including peripheral synovitis, enthesitis, dactylitis, and axial involvement [1]. PsA mostly develops in patients with an established diagnosis of psoriasis (PsO) [1], and its incidence increases with time after the onset of $\mathrm{PsO}$, reaching up to $20 \%$ after 30 years [2]. The identification of predictors of PsA development in $\mathrm{PsO}$ patients is a recognized unmet need in the EULAR recommendations [3]. Recently, through a Delphi consensus, three preclinical PsA phases have been proposed, namely preclinical, subclinical, and prodromal PsA [4]. The recognition of $\mathrm{PsO}$ patients at high risk for transition to PsA could offer the opportunity for (i) early PsA diagnosis through a dedicated follow-up in PsO patients at higher risk for transition [5] and (ii) interception of PsA without extra costs, since a PsO patient in transition could need a tailored therapy that could work both for skin and joints. Interpreting studies on PsA development in PsO patients is challenging, particularly for the distinction between risk factors (including both causality and an etiological function) and predictors (when present, they make the development of the disease more likely, regardless of whether that factor has a causal role) [6]. Accurate prediction of PsA development will facilitate clinical decisionmaking and help design trials for PsA interception by identifying patients at higher risk of transition. This systematic literature review (SLR) and meta-analysis (MA) focuses on predictors, risk factors, and incidence rates of PsA development in PsO patients.

\section{MATERIALS AND METHODS}

The SLR was conducted according to the Preferred Reporting Items for Systematic Reviews and Meta-Analyses statement (PRISMA) [7] and to the Meta-analysis of Observational Studies in Epidemiology (MOOSE) [8]. Two pairs of reviewers (ODL, GC, IG, GM) independently contributed to study selection, data extraction, and quality assessment. Any disagreement was resolved by consensus or by a fifth reviewer 
(AZ). This SLR is based on previously conducted studies and does not contain any studies with human participants or animals performed by any of the authors; therefore, ethical approval was not required.

\section{Literature Search}

MEDLINE, Embase, and Cochrane databases were searched, without time limits, up to February 22, 2020. The terms employed for the search strategy are shown in the Supplementary Material. The research question was rephrased using the Patient, Intervention, Comparator, Outcomes, Study (PICOs) methodology, in order to develop search strategies and define pre-specified inclusion criteria. The population of interest was patients with skin and/or nail $\mathrm{PsO}$ without a diagnosis of PsA. The interventions included symptoms, clinical features, subclinical imaging findings, lifestyle habits, and genetic variants that could predict or be associated with the outcome, defined as occurrence of PsA.

\section{Study Selection}

The records retrieved by the search strategies were transferred into a bibliographic manager software [ZOTERO-Roy Rosenzweig Center for History and New Media, Fairfax, VA, USA]. Reviewers firstly assessed each record by title and abstract, then the full texts were evaluated for final inclusion.

Studies had to be published in English, and no selection based on quality was applied. Eligible studies included SLRs, MAs, and original articles. Regarding the original articles, cohort and case-control study designs were both included. The former were used to assess the potential predictors, i.e., predictive value of signs, symptoms, and acquired factors (e.g., nail dystrophy, arthralgia, PsO severity, obesity, etc.), while the latter were principally employed to measure, when appropriate, the pooled estimates of congenital features and lifestyle habits that are risk factors (e.g., biomarkers, family history of PsA, smoking history, and alcohol consumption, etc.). We excluded abstracts, letters, and editorials.

\section{Data Extraction and Assessment of the Risk of Bias}

Study characteristics and data were extracted on a standardized form. Information from primary studies was captured through summary of findings tables. The risk of bias and methodological quality of the included studies were assessed with different tools, depending on study design: the Newcastle-Ottawa scale (NOS) for observational studies [9] and the ROBIS tool for SLR [10].

\section{Statistical Analyses}

The estimates of the effect values were extracted directly or derived from raw data. The pooled estimates of the risk values were computed when the articles were homogeneous in terms of patient cohorts, follow-up duration, study design, and metrics.

The MA was performed using package 'metafor' in R v 3.6.0 for Windows. Heterogeneity across studies was tested performing $Q-$ test and quantified using the inconsistency statistics $I^{2}$. Fixed- or mixed-effects models were applied as appropriate. Forest plots represent individual and pooled outcome estimates. The publication bias was evaluated through a qualitative inspection of funnel plot and Begg test for testing asymmetry.

\section{RESULTS}

\section{Studies Selected and Characteristics}

The full selection process is shown in Fig. 1. Overall, 26 articles were finally included, 16 cohort (Table 1) and ten case-control studies (Table 2).

\section{Psoriasis Skin and Nail Phenotypes}

Data on PsO severity were extracted from seven cohort studies (Table 3). Pooled estimates were 


\section{PRISMA 2009 Flow Diagram of systematic literature review}

Records identified through database searching: MEDLINE ( $n=1223)$, EMBASE $(n=2562)$, Cochrane $(n=914)$
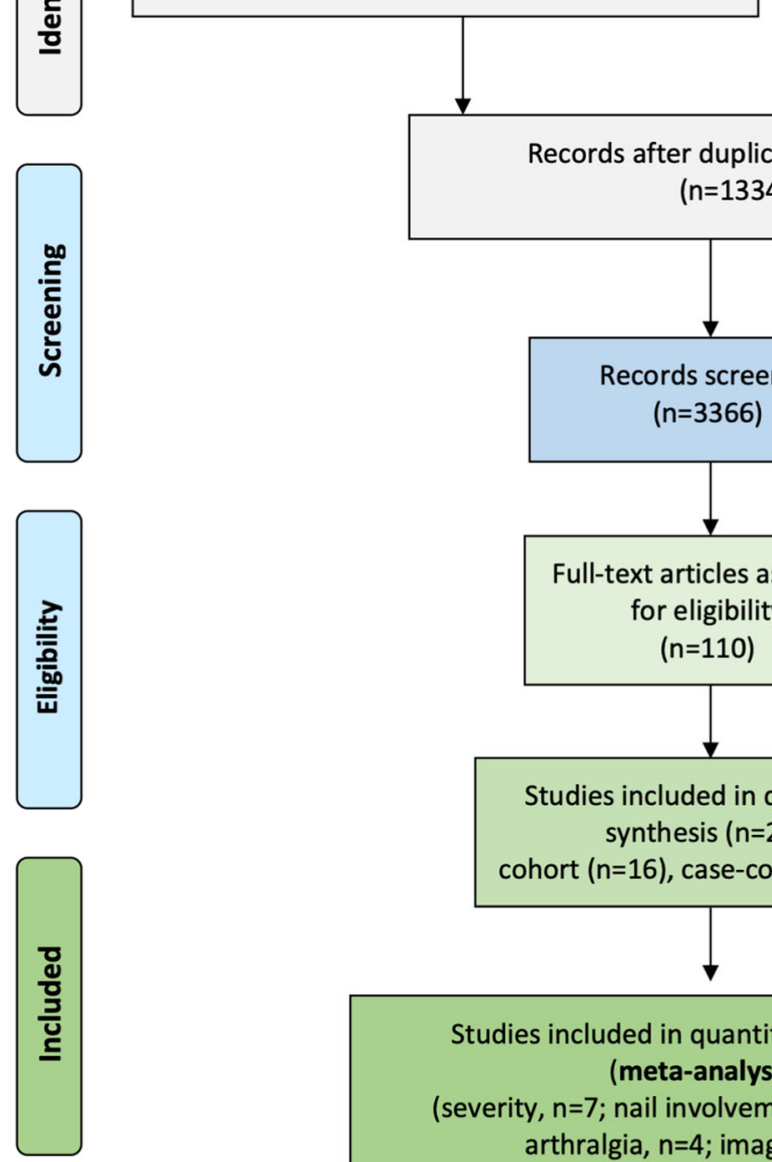

Additional records identified through other sources $(n=1)$

Records excluded $(n=3256)$

Full-text articles excluded ( $n=84)$ : study design ( $n=27)$, not relevant $(n=12)$, population $(n=5)$, outcome $(n=30)$, intervention $(n=10)$

From: Moher D, Liberati A, Tetzlaff J, Altman DG, The PRISMA Group (2009). Preferred Reporting /tems for Systematic Reviews and MetaAnalyses: The PRISMA Statement. PLoS Med 6(7): e1000097. doi:10.1371/journal.pmed1000097

For more information, visit www.prisma-statement.org.

Fig. 1 PRISMA flow diagram 
Table 1 Main characteristics of the 16 cohort studies selected for systematic literature review

\begin{tabular}{|c|c|c|c|c|c|c|c|}
\hline Study, year & Source & $\begin{array}{l}\text { Incident } \\
\text { PsA }\end{array}$ & Total & $\begin{array}{l}\text { PsO } \\
\text { duration }\end{array}$ & $\begin{array}{l}\text { Follow- } \\
\text { up } \\
\text { (years) }\end{array}$ & Factor(s) of interest & $\begin{array}{l}\text { NOS } \\
\text { score }\end{array}$ \\
\hline Li, 2012 & $\begin{array}{l}\text { NHSII } \\
\text { registry }\end{array}$ & 146 & 556 & NA & NA & Obesity & 5 \\
\hline $\mathrm{Li}, 2012$ & $\begin{array}{l}\text { NHSII } \\
\text { registry }\end{array}$ & 157 & 581 & NA & 4.1 & Smoking & 5 \\
\hline Love, 2012 & $\begin{array}{r}\text { Claim DB } \\
(\text { THIN })\end{array}$ & 976 & 75,395 & NA & 4.9 & Obesity & 7 \\
\hline Wilson, 2009 & Claim DB & 57 & 1593 & NA & 13.1 & $\begin{array}{l}\text { Nail dystrophy, type and site of } \\
\text { psoriasis }\end{array}$ & 7 \\
\hline Abji, 2016 & Outpatients & 52 & 620 & & 3.1 & Serum biomarker & 7 \\
\hline Eder, 2016 & $\begin{array}{l}\text { Toronto } \\
\text { Psoriasis } \\
\text { cohort } \\
\text { registry }\end{array}$ & 51 & 464 & $16.4 \pm 14.4$ & 4.1 & $\begin{array}{l}\text { Nail pitting, obesity, smoking, and } \\
\text { alcohol habits, family history of } \\
\text { PsA }\end{array}$ & 8 \\
\hline $\begin{array}{l}\text { Faustini, } \\
2016\end{array}$ & Outpatients & 12 & 41 & $15.2 \pm 15.4$ & 1.2 & $\begin{array}{l}\text { Inflammation and structural damage } \\
\text { detected by imaging }\end{array}$ & 7 \\
\hline Eder, 2017 & $\begin{array}{l}\text { Toronto } \\
\text { Psoriasis } \\
\text { cohort } \\
\text { registry }\end{array}$ & 57 & 410 & $16.5 \pm 2.6$ & 3.8 & Musculoskeletal complaints & 8 \\
\hline $\begin{array}{l}\text { Lewinson, } \\
2017\end{array}$ & $\begin{array}{r}\text { Claim DB } \\
(\text { THIN })\end{array}$ & 1466 & 73,447 & NA & 5.1 & $\begin{array}{l}\text { Depression, obesity, smoking, and } \\
\text { alcohol habits }\end{array}$ & 8 \\
\hline Nguyen, 2017 & $\begin{array}{r}\text { Claim DB } \\
(\text { THIN })\end{array}$ & 4569 & 225,213 & NA & 7.0 & Smoking habits & 7 \\
\hline $\begin{array}{l}\text { Thorarensen, } \\
2017\end{array}$ & $\begin{array}{r}\text { Claim DB } \\
(\text { THIN })\end{array}$ & 1010 & 70,646 & $12.2 \pm 12.0$ & 6.0 & Trauma & 8 \\
\hline Egeberg, 2018 & $\begin{array}{r}\text { Claim DB } \\
\text { (DNPR) }\end{array}$ & 1269 & 10,011 & $7.7 \pm 5.1$ & NA & $\mathrm{PsO}$ severity & 7 \\
\hline Elnady, 2019 & Outpatients & 9 & 104 & $8.7 \pm 7.17$ & 2.0 & $\begin{array}{l}\text { Inflammation and structural damage } \\
\text { detected by imaging }\end{array}$ & 6 \\
\hline Zabotti, 2019 & Outpatients & 6 & 102 & NA & 1.2 & $\begin{array}{l}\text { Inflammation and structural damage } \\
\text { detected by imaging, } \\
\text { musculoskeletal complaints, family } \\
\text { history of PsA }\end{array}$ & 7 \\
\hline Green, 2020 & $\begin{array}{r}\text { Claim DB } \\
\text { (CRPD) }\end{array}$ & 1409 & 90,189 & $5.71 \pm 4.1$ & 5.8 & Obesity, smoking, and alcohol habits & 8 \\
\hline
\end{tabular}


Table 1 continued

\begin{tabular}{llllllll}
\hline Study, year & Source & $\begin{array}{l}\text { Incident } \\
\text { PsA }\end{array}$ & Total & $\begin{array}{l}\text { PsO } \\
\text { duration }\end{array}$ & $\begin{array}{l}\text { Follow- } \\
\text { up } \\
\text { (years) }\end{array}$ & Factor(s) of interest & $\begin{array}{l}\text { NOS } \\
\text { score }\end{array}$ \\
\hline Simon, 2020 & Outpatients & 24 & 114 & $15.8+14.8$ & 2.4 & $\begin{array}{l}\text { Nail involvement, inflammation, } \\
\text { and structural damage detected by } \\
\text { imaging, musculoskeletal } \\
\text { complaints }\end{array}$ & 8 \\
\hline
\end{tabular}

CRPD Clinical Practice Research Datalink, $D B$ database, DNPR Danish National Patient Register, $N A$ not available, THIN The Health Improvement Network

calculated only in a few cases because of the heterogeneity of the data. When expressed as units, the PASI score showed a weak predictive value for the development of PsA [11-13]. On the other hand, a predictive value clearly emerged when the classes of severity were compared (Table 3) [14-17]. The location of psoriasis (i.e., scalp and inverse psoriasis) was associated with development of PsA in only one study [18]; this has not been replicated in other studies.

With regard to nail involvement $[11,12,19]$, an increased risk of PsA among PsO patients in terms of cumulative incidence did not emerge (RR 0.69 [95\% CI $0.37-1.27], I^{2}=50.33 \%$, $p=0.1335$ ) (Fig. 2). However, the three pertinent studies enrolled a relatively small sample size, and the patients were followed only for an average of 2 years. In terms of hazard ratio, only the large and long-term follow-up study of Wilson [18] supported the nail involvement as predictor of PsA in both univariate and multivariate analysis.

Focusing on type of psoriatic nail lesions, the pooled estimate from two cohort studies $[13,14]$ supported nail pitting as remarkable predictor of PsA (pooled HR 2.14 [1.32; 3.46], $\left.I^{2}=0.00 \%, p=0.8366\right)$ but the data were available in univariate analysis only. However, this finding was confirmed in the former article [14] when the nail pitting was considered as timevarying covariate in a multivariate model (HR 2.51 [95\% CI 1.37-4.49]).

\section{Musculoskeletal (MSK) Symptoms}

Data were retrieved from four studies $[5,11,13,19]$. The risk of PsA development in $\mathrm{PsO}$ subjects with arthralgia was about two times greater than in subjects without arthralgia (pooled RR 2.15 [95\% CI 1.16-3.99], $I^{2}=0.00 \%$, $p=0.7797$ ) (Fig. 2). In these three studies, the patients were followed for a comparable period of time $(1.2 \pm 0.2$ vs. $1.2 \pm 0.4$ days vs. $2.4 \pm 1.5$ years, respectively). Of note, arthralgia was defined differently: in Faustini et al. as at least one tender joint; in Zabotti et al. as recent onset ( $\leq 12$ months) of non-inflammatory joint and/or entheseal pain, without current or past inflammatory signs/symptoms, and with CASPAR criteria for a diagnosis of PsA not being fulfilled; and in Simon et al. as arthralgia in terms of VAS and tender joints. Arthralgia as predictor of PsA (in female gender only) was confirmed in the cohort study of Eder et al. [13] in both univariate (HR 2.38 [95\% CI 1.08-5.26]) and multivariate (HR 2.59 [1.15-5.88]) analysis over a longer observational time (mean followup time $3.8+2.1$ years).

\section{MSK Inflammation and Structural Damage Detected by Imaging}

The information was retrieved from four prospective studies [5, 11, 12, 19] (suppl Table 1). PsO patients with imaging-detected MSK inflammation (e.g., synovitis, enthesitis, tenosynovitis) or imaging-detected structural damage (e.g., erosion, entheseal new bone 
Table 2 Main characteristics of the ten case-control studies selected for systematic literature review

\begin{tabular}{|c|c|c|c|c|c|c|}
\hline Study, year & Cases & Controls & $\begin{array}{l}\text { Mean age at } \mathrm{PsO} \\
\text { onset in cases }\end{array}$ & $\begin{array}{l}\text { Mean age at } \mathrm{PsO} \\
\text { onset in controls }\end{array}$ & Factor(s) of interest & $\begin{array}{l}\text { NOS } \\
\text { score }\end{array}$ \\
\hline $\begin{array}{l}\text { Thumboo, } \\
2002\end{array}$ & 60 & 120 & 31.6 & 31.7 & Family history of PsA & 8 \\
\hline Julià, 2012 & 955 & 1050 & 30.1 & 29.6 & Genetic variants & 8 \\
\hline Duffin, 2009 & 181 & 334 & 25.9 & 22.7 & Genetic variants & 8 \\
\hline Tey, 2010 & 134 & 266 & 30 & 31 & Family history of PsA & 8 \\
\hline Eder, 2011 & 555 & 342 & 27.8 & 29.8 & Genetic variants & 7 \\
\hline Eder, 2011 & 159 & 159 & 27.7 & 29.8 & $\begin{array}{l}\text { Family history of PsA, alcohol } \\
\text { and smoking habits }\end{array}$ & 9 \\
\hline Eder, 2012 & 728 & 404 & 27.8 & 30.2 & Alcohol and smoking habits & 7 \\
\hline Isik, 2016 & 58 & 71 & - & 28.5 & Genetic variants & 7 \\
\hline $\begin{array}{l}\text { Tsuruta, } \\
2017\end{array}$ & 55 & 276 & - & 42 & Alcohol and smoking habits & 5 \\
\hline $\begin{array}{l}\text { Smolnikova, } \\
2019\end{array}$ & 99 & 77 & 25 & 22 & Genetic variants & 4 \\
\hline
\end{tabular}

formation) were almost four times more likely to develop PsA (pooled RR 3.72 [2.12; 6.51], $I^{2}=0.00 \%, p=0.6008$ ) (Fig. 2). Of note, imaging-identified MSK inflammation was defined differently in the studies. In Faustini et al. [11], the MRI of the dominant hand was performed and MRI positivity, defined as the presence of synovitis and/or osteitis, influenced the risk of patients with $\mathrm{PsO}$ to progress to PsA. In Elnady et al. [12] and Zabotti et al. [5], MSK ultrasonography (MSK-US) of peripheral joints and entheses was the index test used for the detection of subclinical MSK inflammation. In the former PsO, patients who developed PsA showed a higher prevalence of baseline sonographic enthesitis and higher synovitis scores. In the latter [5], only baseline sonographic enthesitis was found to influence clinical PsA development. Lastly, Simon et al. [19] highlighted that structural entheseal lesions and low volumetric bone mineral density at entheseal and intra-articular sites evaluated by high-resolution peripheral quantitative computed tomography (HR-pQCT) were associated with PsA development.

\section{Comorbidities}

Two prospective articles mainly focused on obesity [20, 21]. Compared with subjects with a normal weight, higher categories of BMI significantly increased the risk of PsA (adj. HR [95\% CI] of total effect: 1.17 [1.04-1.31] (BMI 25-29.9), 1.57 [1.38-1.80] (BMI 30.0-34.9), 1.96 [1.68-1.2.29] (BMI $\geq 35)$ in Love et al. [20]; adj. HR [95\% CI] of total effect: 1.83 [1.15-2.89] (BMI 25-29.9), $3.12 \quad$ [1.90-5.11] (BMI $30.0-34.9), 6.46$ [4.11-10.16] $(\mathrm{BMI} \geq 35)$ in $\mathrm{Li}$ et al. [21]). By focusing the analysis on subjects developing PsO, the authors saw a similar positive predictive value, indicating an increased risk of PsA associated with obesity among patients with PsO. No pooled estimate was calculated due to the significant differences in the enrolled populations. Indeed, Li's research [21] refers to the Nurses' Health Study II, where the 
sample population included females within the age range of 25-42, employed as nurses.

However, with these differences in mind, both the studies achieved the conclusion that obesity was associated with an increased risk of PsA incidence among PsO patients, emphasizing the need of a good control of the patients' weight.
Fig. 2 Forest plot of the pooled estimates of the main potential predictors of PsA, nail involvement (A), musculoskeletal complaints $(\mathbf{B})$, and inflammation and structural damage detected by imaging $(\mathbf{C})$

Other studies included an estimate of the effect of obesity $[14,15,17]$, but we did not

Table 3 Data extracted and when appropriate pooled in order to estimate the role of PASI score as predictor variable of increased risk of PsA

\begin{tabular}{|c|c|c|}
\hline $\begin{array}{l}\text { Author, } \\
\text { year }\end{array}$ & Definition & Risk measure \\
\hline $\begin{array}{c}\text { Faustini, } \\
2015\end{array}$ & Effect size $[95 \% \mathrm{CI}]:-0.18[-0.84 ; 0.48]$ & $\begin{array}{l}\text { Pooled effect size }[95 \% \mathrm{CI}] \text { : } \\
0.06[-0.51 ; 0.63]\end{array}$ \\
\hline $\begin{array}{r}\text { Elnady, } \\
2019\end{array}$ & Effect size $[95 \% \mathrm{CI}]: 0.79[-0.37 ; 1.95]$ & \\
\hline Eder, 2016 & Categorical: $10-20$ vs. $<10$ or $>20$ vs. $<10$ & $\begin{array}{l}\text { HR }[95 \% \text { CI]: } \\
\text { - Unadjusted model } \\
\text { 10-20 vs. }<10: 1.35[0.63 \text {; } \\
2.91] \\
>20 \text { vs. }<10: 3.86[1.27 \text {; } \\
11.7] \\
\text { - Adjusted model } \\
10-20 \text { vs. }<10: 1.16[0.50 ; \\
2.64] \\
>20 \text { vs. }<10: 5.39[1.64 ; \\
17.7]\end{array}$ \\
\hline Eder, 2017 & Continuous (score unit) & $\begin{array}{l}\text { HR }[95 \% \mathrm{CI}]: \\
\text { - Unadjusted model } \\
1.05[1.01 ; 1.09]\end{array}$ \\
\hline $\begin{array}{l}\text { Lewinson, } \\
2017\end{array}$ & $\begin{array}{l}\text { The presence of mild vs. moderate-severe psoriasis was defined from } \\
\text { medication usage as already used (Gelfand et al., 2006; Kurd et al., 2010) }\end{array}$ & $\begin{array}{l}\text { HR }[95 \% \mathrm{CI}]: \\
\text { - Adjusted model } \\
\text { Moderate/severe vs. mild: } \\
\quad 5.02[4.18 ; 6.04]\end{array}$ \\
\hline $\begin{array}{l}\text { Egeberg, } \\
2018\end{array}$ & As severe if patients received systemic therapy for the condition & $\begin{array}{l}\mathrm{RR}[95 \% \mathrm{CI}]: \text { severe vs. } \\
\text { mild: } 1.31[1.18 ; 1.46]\end{array}$ \\
\hline $\begin{array}{l}\text { Green, } 2020 \\
\text { (BJD) }\end{array}$ & $\begin{array}{l}\text { As severe if patients had prescription for medicine consistent with the } \\
\text { treatment of severe disease or evidence of a referral to dermatologist }\end{array}$ & $\begin{array}{l}\text { RR }[95 \% \mathrm{CI}]: \text { severe vs. } \\
\text { mild: } 2.79[2.49 ; 3.13]\end{array}$ \\
\hline
\end{tabular}




\section{(A) Nail involvement}

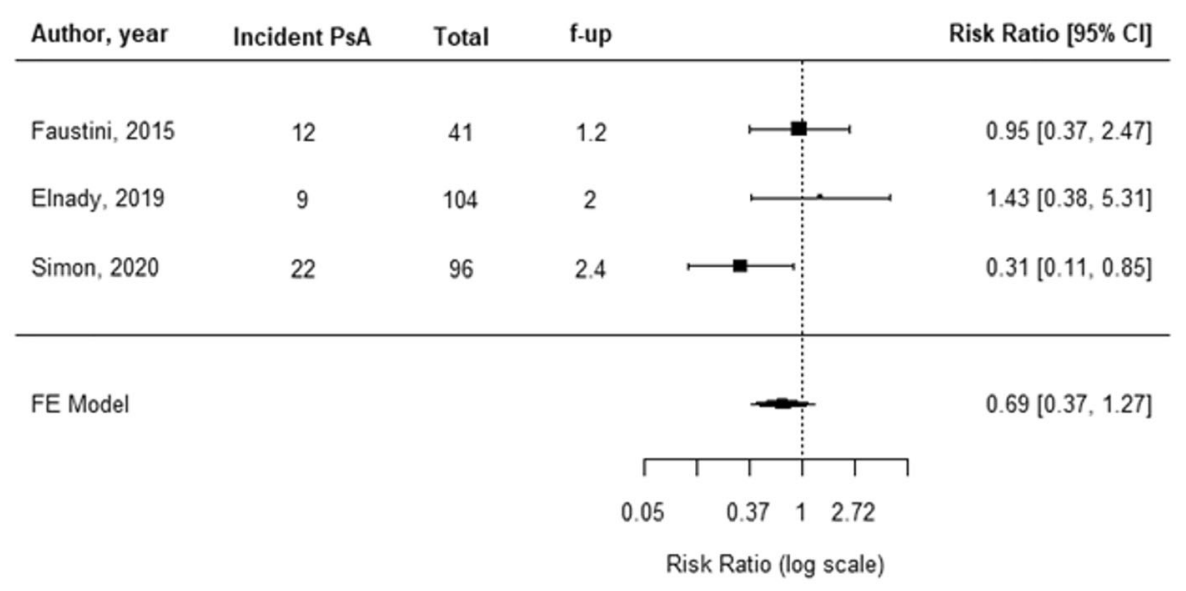

\section{(B) Musculoskeletal (MSK) complaints}

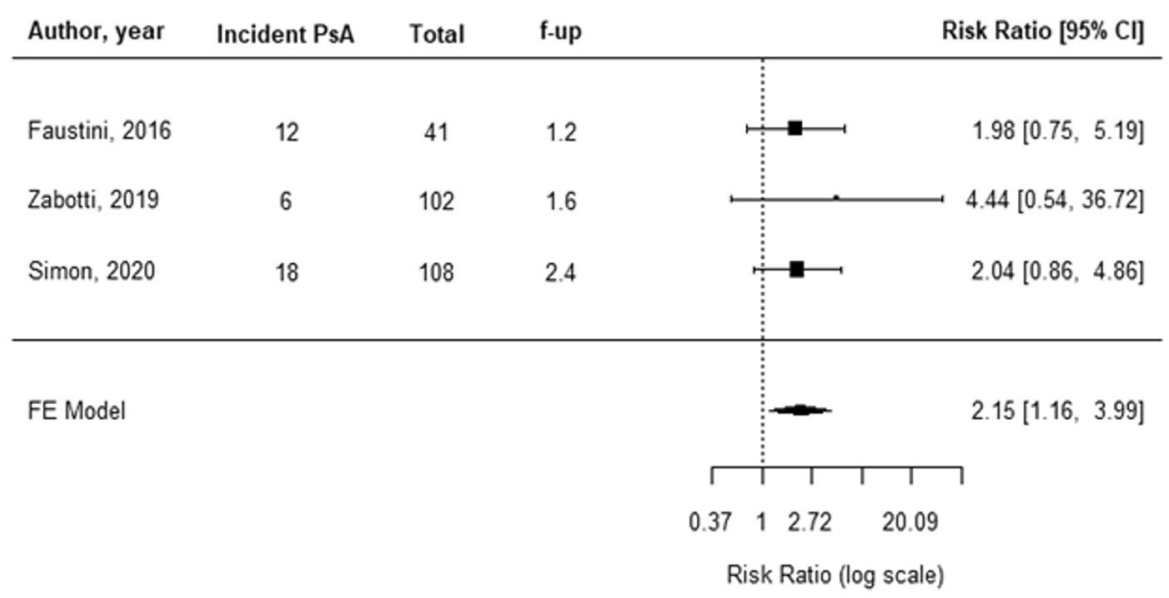

\section{(C) Inflammation and structural damage detected by imaging}

\begin{tabular}{|c|c|c|c|c|c|c|}
\hline Author, year & Incident PsA & Total & f-up & & & Risk Ratio $[95 \% \mathrm{Cl}]$ \\
\hline Faustini, 2016 & 12 & 41 & 1.2 & & $=$ & $2.10[0.75,5.90]$ \\
\hline Elnady, 2019 & 9 & 104 & 2 & & & $5.38[1.17,24.63]$ \\
\hline Zabotti, 2019 & 6 & 102 & 1.6 & & & $6.86[0.83,56.63]$ \\
\hline Simon, 2020 & 24 & 114 & 2.4 & & 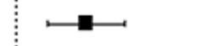 & $4.32[1.96,9.55]$ \\
\hline \multirow[t]{3}{*}{ FE Model } & & & & & - & $3.72[2.12,6.51]$ \\
\hline & & & & $\Gamma$ & $T$ & 7 \\
\hline & & & & 0.37 & $\begin{array}{lll}1 & 2.72 & 20.09\end{array}$ & 148.41 \\
\hline
\end{tabular}


consider these due to the lack of causal inference approach.

Also, depression seems to be related to an increased systemic inflammation that likely predispose PsO patients to PsA [15]. In their population-based study, Lewinson and colleagues [15] went beyond the concept of physical and cosmetic disability as the unique determinants of depression status, showing a temporal relationship between $\mathrm{PsO}$, major depressive disorder, and PsA (adjusted HR 1.37 [95\% CI 1.05-1.80], $p=0.021$ ).

\section{Environmental Triggers}

\section{Smoking History}

The findings on smoking and alcohol habits are controversial. In case-control studies, smoking and drinking history information was retrieved through questionnaires that investigated the patient's past habits over a period over 1-10 years before the diagnosis of PsA. Regarding the pooled estimates, smoking was not significantly associated to arthritis development in both univariate (OR 0.67 [95\% CI 0.40-1.13], $\left.I^{2}=0.00 \%, p=0.526\right)[22-24]$ and multivariate analysis (OR $0.71 \quad$ [95\% CI $0.38-1.32]$, $\left.I^{2}=0.00 \%, p=0.639\right)[22,23]$, even though with a trend towards a protective effect. Although in a heterogeneous manner, three out of five cohort studies confirmed this trend with the following non-pooling estimates (current smokers vs. non-smokers at baseline): adjusted OR equals to 0.94 [95\% CI 0.76-1.16] [17], univariate HR equals to 1.36 [95\% CI $0.68-2.73$ ] [14], and multivariate HR equals to 0.87 [95\% CI 0.80-0.94] [15]. On the other hand, Li et al. [25] found current smoking positively related with the risk of PsA when the association was measured among the total participants of the Nurses Health Study II (multivariate adjusted RR: 3.12 [2.07-4.69]), and also among PsA cases but only when restricted to severe phenotypes (multivariate adjusted RR 5.34 [2.78-10.28]). The smoking paradox was explained by Nguyen [26] clarifying that a bias is introduced when conditioning on a causal intermediate factor. Indeed, the relationship between smoking and PsA risk was positive when assessed over the general population (current smokers vs. nonsmokers, HR 1.27 [95\% CI 1.19-1.36]), but negative when limited to patients with $\mathrm{PsO}$ that is the causal intermediate variable (HR 0.89 [95\% CI 0.84-0.95]). The former is a measure of the total effect while the latter of the direct effect of smoking. Also, the effect of uncontrolled confounding could concur in the biased estimate of the smoking status.

\section{Alcohol Consumption}

The role of daily alcohol consumption is still debated. In case-control studies, the association did not emerge significantly neither through univariate pooled estimates (OR 1.09 [0.58-2.03], $\left.I^{2}=0.00 \%, p=0.948\right)$ nor through combined multivariate analyses (OR 1.37 [0.62-3.06], $\left.I^{2}=0.00 \%, \quad p=0.554\right)$ [22-24]. Again, the estimate of the relative risk of alcohol was reported in different ways among cohort studies making not possible to calculate a pooled value: in the study of Green [17], the comparison was between moderate or heavy drinkers vs. non-drinkers (adjusted OR 1.57 $[95 \%$ CI 1.16-2.11] and 0.94 [95\% CI $0.56-1.58])$; in the studies of Eder [14, 22, 23] and Lewinson [15], the results were reported as daily vs. none (univariate HR 1.02 [0.40-2.59]) or social vs. none (univariate HR 1.02 [95\% CI 0.40-2.59]), and generic alcohol use vs. none (adjusted HR 1.01 [0.85-1.20]), respectively.

\section{Trauma}

The hypothesis that trauma could trigger PsA has arisen from several case-control studies or case series, while for the first time, the study by Thorarensen and colleagues [27] investigated trauma in a longitudinal setting. By retrieving data from a UK claims database (THIN), the authors had the opportunity to follow more than 70,000 patients suffering from $\mathrm{PsO}$, of whom almost $20 \%$ reported any trauma after the diagnosis of PsO. To avoid an unbalanced comparison, patients with $\mathrm{PsO}$ exposed to trauma were randomly matched to patients with $\mathrm{PsO}$ without trauma exposure according to four factors including age, gender, duration of psoriasis, and the date of entry into the THIN database. This ensured that patients exposed to 
Table 4 Incidence rate (IR) per 100 patient-years and related $95 \%$ confidence intervals $(95 \% \mathrm{CI}$ ) calculated or extracted from every cohort study whenever possible and stratified according to source of incident or prevalent $\mathrm{PsO}$

\begin{tabular}{|c|c|c|c|}
\hline Author, year & $N$ events & $\begin{array}{l}\text { Person- } \\
\text { years }\end{array}$ & IR $[95 \% \mathrm{CI}]$ \\
\hline \multicolumn{4}{|l|}{ Population-based } \\
\hline Wilson, 2009 & 57 & 20,936 & $0.27[0.21-0.35]$ \\
\hline Love, 2012 & 976 & 368,302 & $0.27[0.25-0.28]$ \\
\hline $\begin{array}{l}\text { Lewinson, } \\
2017\end{array}$ & 1466 & $374,579.7$ & $0.39[0.37-0.41]$ \\
\hline Nguyen, 2017 & 4569 & $1,978,228$ & $0.23[0.22-0.24]$ \\
\hline $\begin{array}{l}\text { Thorarensen, } \\
2017\end{array}$ & 1010 & 425,120 & $0.24[0.22-0.25]$ \\
\hline Green, 2020 & 1409 & 521,826 & $0.27[0.26-0.28]$ \\
\hline \multicolumn{4}{|l|}{ Psoriasis Registry } \\
\hline Eder, 2016 & 51 & 1880.9 & $2.7[2.1-3.6]$ \\
\hline Eder, 2017 & 57 & 1562.1 & $3.7[2.8-4.7]$ \\
\hline \multicolumn{4}{|l|}{ Outpatients } \\
\hline Abji, 2016 & 52 & 1922 & $2.7[2.0-3.5]$ \\
\hline $\begin{array}{l}\text { Faustini, } \\
2016^{\mathrm{a}}\end{array}$ & 12 & 49.2 & $24.4[12.6-42.6]$ \\
\hline Elnady, 2019 & 9 & 208 & $4.3[2.0-8.2]$ \\
\hline $\begin{array}{l}\text { Zabotti, } \\
2019^{\mathrm{a}}\end{array}$ & 6 & 120.4 & $4.9[1.8-10.8]$ \\
\hline Simon, $2020^{\mathrm{a}}$ & 24 & 273.6 & $9.7[6.2-14.5]$ \\
\hline
\end{tabular}

${ }^{a}$ Studies including $\mathrm{PsO}$ patients with arthralgia (i.e., prodromal PsA). The IRs subdivided for the presence of arthralgia were as follows: Faustini, 2016: $\mathrm{PsO}$ without arthralgia $=$ IR 17.4 [5.6-40.5]; $\mathrm{PsO}$ with arthralgia $=\mathrm{IR}$ 34.3 [13.8-70.7]; Zabotti, 2019: $\mathrm{PsO}$ without arthralgia = IR 1.34 [0.0-7.5]; PsO with arthralgia = IR 10.9 [3.5-25.4]; Simon, 2020: $\mathrm{PsO}$ without arthralgia $=$ IR 5.9 [2.4-12.2]; $\mathrm{PsO}$ with arthralgia $=$ IR 12.5 [6.2-22.4]

trauma and unexposed controls were followed during similar periods of time. The authors concluded with some limitations that bone and joint trauma were independent and diseasespecific risk factors for PsA (HR 1.46 [95\% CI 1.04-2.04 and HR 1.50 [95\% CI 1.19-1.90], respectively).

\section{Family History for PsA}

Data on family history of PsA were retrieved from five studies, three with a case-control design $[5,14,22,28,29]$. The number of PsA/ $\mathrm{PsO}$ diagnosis among subjects with family history of PsA was extremely low, leading to imprecise estimates of the risk. However, the pooled value of association was not affected by heterogeneity $\left(I^{2}=32.99 \%, p=0.225\right)$ and the narrowed confidence intervals suggested a reliable true effect (OR 4.43 [95\% CI 1.80-10.88]). This finding was not confirmed in the cohort study of Zabotti et al. [5], where the estimate of the cumulative incidence revealed a clear-cut not significant effect (RR 1.20 [0.15-9.58]) and in Eder et al. [14], who reported a RR of 1.42 [95\% CI $0.82-2.45, p=0.21$ ] in the univariate analysis with no need to further consider the factor at a multivariate level.

\section{Serum Biomarkers and Genetic Factors}

Soluble proteins could provide invaluable tools as prognostic markers of PsA susceptibility. CXCL10 was previously found consistently upregulated in PsA compared with PsO [30]. Later, the same research group confirmed the involvement of CXCL10 in the pathogenesis of PsA [31] by prospectively investigating CXCL10 serum concentrations in serum samples and gene expression in synovial fluid and blood. At baseline, CXCL10 levels looked higher in patients who developed PsA than in patients who did not (493 vs. $371 \mathrm{pg} / \mathrm{ml}, p=0.005$ ), and then gradually decreased after PsA diagnosis; concurrently, gene expression was increased in synovial fluid rather than in blood. The association with conversion status of $\mathrm{PsO}$ patients was confirmed at a multivariate level after adjustment for age, sex, duration of psoriasis, and duration of follow-up (OR 1.3 [95\% CI 1.1-1.5, $p=0.004])$. The a priori exclusion of studies with a cross-sectional design negatively impacted the selection of studies focusing on possible genetic markers. Further details are included in the Supplemental Material [31-35]. 


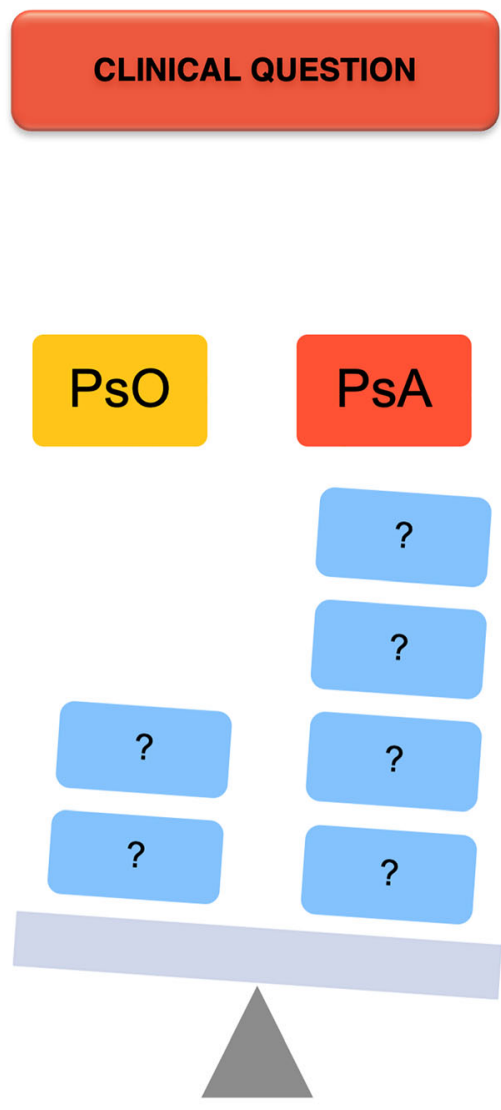

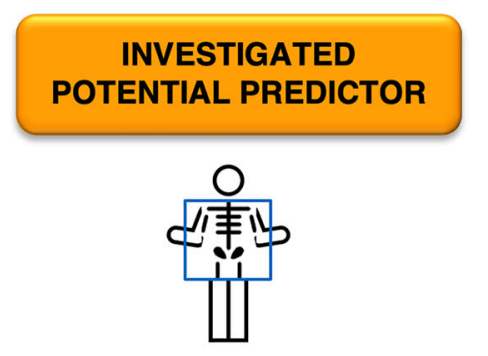
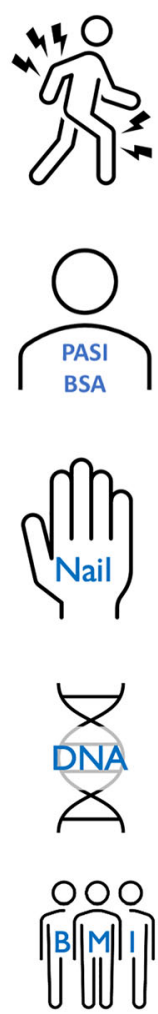

\section{SYNTHESIS OF EVIDENCE}

imaging-detected MSK inflammation synovitis, enthesitis, tenosynovitis imaging-detected structural damage erosion, entheseal new bone formation

\section{Arthralgia}

PsO severity

$$
\text { Nail involvement }
$$

Family history for PsA

BMI (Body Mass Index)

Fig. 3 Synthesis of the potential predictors of PsA development in PsO patients

\section{The Incidence Rate of PsA in PsO Patients}

The incidence rate per 100 patient-years (IR) varied significantly according to the study type, ranging from 0.23 [95\% CI $0.22-0.24$ ] to 0.39 [95\% CI 0.37-0.41] [15, 26] and from $2.7[95 \%$ CI 2.1-3.6] to 3.7 [2.8-4.7] [13] in population and psoriasis registry studies, respectively (Table 4). As expected, the IR broadly increased when estimated in an outpatient setting; indeed the cohorts were selected a priori, including for example several PsO patients in suspected prodromal phase of PsA (i.e., PsO with arthralgia) $[5,11,19]$. Specifically, the IR per 100 patient- years varied from $1.34[0.0-7.5]$ to 17.4 [5.6-40.5] in PsO patients without arthralgia $[5,11]$, and from 10.9 [3.5-25.4] to 34.3 [13.8-70.7] in PsO patients with arthralgia $[5,11]$ (Table 4). The IR per 100 patient-years of the study by Faustini et al. is remarkably high, and not comparable with the IR of the other outpatient-based studies and registry.

\section{DISCUSSION}

Identifying predictors and risk factors for the development of PsA among PsO patients is a crucial step for the understanding of the 
pathophysiology of PsA and for the recognition of PsO patients that could benefit from PsA interception or early intervention near to PsA onset [36]. The SLR and MA results provide important insights regarding the features of $\mathrm{PsO}$ patients at increased risk of PsA. The investigated potential predictors are synthetized in Fig. 3.

Among skin predictors, the presence of severe $\mathrm{PsO}$ is associated with PsA development, while the location of PsO (e.g., scalp or inverse $\mathrm{PsO})$ needs to be confirmed.

In one long-term study [18], nail psoriasis was associated with PsA development. In three other studies, nail involvement "per se" did not emerge as a predictor of PsA occurrence but this finding was probably affected by the small sample size of the studies and by the lack of a reasonable time frame for observation. More recently, two retrospective cohort studies $[37,38]$, not included in this SLR since they were published in July 2021, confirmed the original observation of Wilson et al. supporting $\mathrm{PsO}$ nail involvement as predictor of PsA development. Among PsO nail lesions, only nail pitting was selected as a possible predictor [39].

Special attention has recently been paid to PsA interception of PsO patients with subclinical inflammation detected by imaging and/or prodromal symptoms of PsA [40, 41]. The SLR and MA highlight that the detection of arthralgia or an imaging positive for inflammation could be currently considered a short-term predictor of PsA development. The risk to develop PsA in PsO with arthralgia is two times greater than in PsO without arthralgia, while PsO patients with imaging detected MSK inflammation or imaging detected structural damage were four times more likely to develop PsA. These results clearly underline the importance of MSK complaints referred by the patients and the subclinical disease detected by imaging to stratify $\mathrm{PsO}$ patients at imminent risk for PsA development. However, the role of imaging as predictor needs to be considered with caution since further studies are needed to identify the proper imaging modalities for the detection of subclinical PsA and which imaging detected subclinical signs could be considered as predictors of PsA development.
The IR in PsO patients with arthralgia is significantly higher compared to those without, confirming that arthralgia is a key sign of prodromal PsA. The definition of arthralgia and the MSK complaints specific for progression are crucial steps to identifying $\mathrm{PsO}$ patients at imminent risk to develop PsA. Furthermore, in this "PsO to PsA march", also the definition of PsA diagnosis deserves discussion since the Classification for Psoriatic Arthritis (CASPAR) [42] criteria were meant for classification and might not be adequate to diagnose PsA at an early stage.

Other predictors, including comorbidities (i.e., obesity and depression), family history of PsA, and environmental triggers, like trauma, could assist clinicians and researchers for the characterization of $\mathrm{PsO}$ patients at high risk for PsA development but further longitudinal studies will be needed.

The results of this SRL with MA are limited by the relatively small amount of available data. Indeed, in many cases, we could not pool the results because of lack of homogeneity both in the study procedures and in the outcome measurement (e.g., severity).

\section{CONCLUSIONS}

This study provides a profile of the PsO patients at higher risk of developing PsA and represents a benchmark for a preliminary characterization of the PsO to PsA march and for the design of PsA interception trial in $\mathrm{PsO}$ patients. More data from longitudinal studies are clearly needed, as well as an improved knowledge on the preclinical phases of PsA and a better definition of early disease [43].

\section{ACKNOWLEDGEMENTS}

Funding. Medical writing support (including development of a draft outline and subsequent drafts in consultation with the authors, assembling tables and figures, fact checking, and referencing) was provided by Francesca Pregnolato, and an unrestricted educational 
grant from Novartis Farma, Italy. The authors would also like to thank HPS (Health Publishing and Services Srl) for assisstance with the journal's Rapide Service Fee. This support was funded by Novartis Farma, Italy.

Authorship. All named authors meet the International Committee of Medical Journal Editors criteria for authorship for this article, take responsibility for the integrity of the work as a whole, and have given their approval for this version to be published.

Authorship Contributions. AZ, ODL conceived and designed the study; AZ, ODL, GS, IG, GM, GC prepared the material and collected and analyzed the data; AZ, ODL, GS performed the statistical analysis; AZ, ODL, DMG wrote the first draft; All authors critically revised the first draft for important intellectual content. All authors approved the final version to be submitted. All authors agree to be accountable for all aspects of the work in ensuring that questions related to the accuracy or integrity of any part of the work are appropriately investigated and resolved.

Prior Presentation. The study was presented as poster presentation at the Annal European Congress of Rheumatology in June 2021 (number POS0145).

Disclosures. Alen Zabotti, Orazio De Lucia, Garifallia Sakellariou, Alberto Batticciotto, Gilberto Cincinelli, Ivan Giovannini, Luca Idolazzi, Gabriella Maioli, Ilaria Tinazzi, Daniel Aletaha, Salvatore De Vita, Antonio Marchesoni, Josef Smolen, Annamaria Iagnocco, Dennis McGonagle, Roberto Caporali has nothing to disclose.

Compliance with Ethics Guidelines. This review is based on previously conducted studies and does not contain any studies with human participants or animals performed by any of the authors; therefore, ethical approval was not required.
Data Availability. The review protocol and full data are available from the corresponding author upon request.

Open Access. This article is licensed under a Creative Commons Attribution-NonCommercial 4.0 International License, which permits any non-commercial use, sharing, adaptation, distribution and reproduction in any medium or format, as long as you give appropriate credit to the original author(s) and the source, provide a link to the Creative Commons licence, and indicate if changes were made. The images or other third party material in this article are included in the article's Creative Commons licence, unless indicated otherwise in a credit line to the material. If material is not included in the article's Creative Commons licence and your intended use is not permitted by statutory regulation or exceeds the permitted use, you will need to obtain permission directly from the copyright holder. To view a copy of this licence, visit http://creativecommons.org/licenses/by$\mathrm{nc} / 4.0 /$.

\section{REFERENCES}

1. Gladman DD, Antoni C, Mease P, Clegg DO, Nash P. Psoriatic arthritis: epidemiology, clinical features, course, and outcome. Ann Rheum Dis. 2005;64(Suppl 2):ii14-17.

2. Christophers E, Barker JNWN, Griffiths CEM, Daudén $E$, Milligan G, Molta $C$, et al. The risk of psoriatic arthritis remains constant following initial diagnosis of psoriasis among patients seen in European dermatology clinics. J Eur Acad Dermatol Venereol. 2010;24:548-54.

3. Gossec L, Baraliakos X, Kerschbaumer A, de Wit M, McInnes I, Dougados $\mathrm{M}$, et al. EULAR recommendations for the management of psoriatic arthritis with pharmacological therapies: 2019 update. Ann Rheum Dis. 2020;79:700-12.

4. Scher JU, Ogdie A, Merola JF, Ritchlin C. Preventing psoriatic arthritis: focusing on patients with psoriasis at increased risk of transition. Nat Rev Rheumatol Nat Publ Group. 2019;15:153-66.

5. Zabotti A, McGonagle DG, Giovannini I, Errichetti E, Zuliani F, Zanetti A, et al. Transition phase towards psoriatic arthritis: clinical and 
ultrasonographic characterisation of psoriatic arthralgia. RMD Open. 2019;5:e001067.

6. Ogdie A. The preclinical phase of PsA: a challenge for the epidemiologist. Ann Rheum Dis. 2017;76: 1481-3.

7. Moher D, Liberati A, Tetzlaff J, Altman DG, PRISMA Group. Preferred reporting items for systematic reviews and meta-analyses: the PRISMA statement. PLoS Med. 2009;6:e1000097.

8. Stroup DF, Berlin JA, Morton SC, Olkin I, Williamson GD, Rennie D, et al. Meta-analysis of observational studies in epidemiology: a proposal for reporting. Meta-analysis Of Observational Studies in Epidemiology (MOOSE) group. JAMA. 2000;283:2008-12.

9. Ottawa Hospital Research Institute [Internet]. http://www.ohri.ca/programs/clinical_ epidemiology/oxford.asp. Accessed 17 Mar 2021.

10. Whiting P, Savović J, Higgins JPT, Caldwell DM, Reeves BC, Shea B, et al. ROBIS: a new tool to assess risk of bias in systematic reviews was developed. J Clin Epidemiol. 2016;69:225-34.

11. Faustini F, Simon D, Oliveira I, Kleyer A, Haschka J, Englbrecht M, et al. Subclinical joint inflammation in patients with psoriasis without concomitant psoriatic arthritis: a cross-sectional and longitudinal analysis. Ann Rheumatic Dis. 2016;75:2068-74 (G. Schett, Department of Internal Medicine 3, Rheumatology and Immunology, University of Erlangen-Nuremberg, Ulmenweg 18, Erlangen, Germany).

12. Elnady B, El Shaarawy NK, Dawoud NM, Elkhouly T, Desouky DE-S, Elshafey EN, et al. Subclinical synovitis and enthesitis in psoriasis patients and controls by ultrasonography in Saudi Arabia; incidence of psoriatic arthritis during two years. Clin Rheumatol. 2019;38:1627-35 (J.J. Rasker, Department Psychology, Health and Technology, Faculty of Behavioral, Management and Social sciences, University of Twente, PO box 217, Enschede, Netherlands).

13. Eder L, Polachek A, Rosen CF, Chandran V, Cook R, Gladman DD. The development of psoriatic arthritis in patients with psoriasis is preceded by a period of nonspecific musculoskeletal symptoms: a prospective cohort study. Arthritis Rheumatol (Hoboken, NJ). 2017;69:622-9.

14. Eder L, Haddad A, Rosen CF, Lee K-A, Chandran V, Cook $\mathrm{R}$, et al. The Incidence and risk factors for psoriatic arthritis in patients with psoriasis: a prospective cohort study. Arthritis Rheumatol. 2016;68:915-23.
15. Lewinson RT, Vallerand IA, Lowerison MW, Parsons LM, Frolkis AD, Kaplan GG, et al. Depression is associated with an increased risk of psoriatic arthritis among patients with psoriasis: a population-based study. J Investig Dermatol. 2017;137: 828-35 (C. Barnabe, University of Calgary, 3330 Hospital Drive NW, Calgary, Alberta, Canada).

16. Egeberg A, Skov L, Zachariae C, Gislason GH, Thyssen JP, Mallbris L, et al. Duration of psoriatic skin disease as risk factor for subsequent onset of psoriatic arthritis. Acta Derm Venereol. 2018;98: 546-50.

17. Green A, Shaddick G, Charlton R, Snowball J, Nightingale A, Smith C, et al. Modifiable risk factors and the development of psoriatic arthritis in people with psoriasis. Br J Dermatol. 2020;182:714-20.

18. Wilson FC, Icen M, Crowson CS, McEvoy MT, Gabriel SE, Kremers HM. Incidence and clinical predictors of psoriatic arthritis in patients with psoriasis: a population-based study. Arthritis Rheum. 2009;61:233-9.

19. Simon D, Tascilar K, Kleyer A, Bayat S, Kampylafka E, Sokolova M, et al. Structural entheseal lesions in patients with psoriasis are associated with an increased risk of progression to psoriatic arthritis. Arthritis Rheumatol. 2020. https://doi.org/10.1002/ art.41239.

20. Love TJ, Zhu Y, Zhang Y, Wall-Burns L, Ogdie A, Gelfand JM, et al. Obesity and the risk of psoriatic arthritis: a population-based study. Ann Rheum Dis. 2012;71:1273-7.

21. Li W, Han J, Qureshi AA. Obesity and risk of incident psoriatic arthritis in US women. Ann Rheum Dis. 2012;71:1267-72.

22. Eder L, Law T, Chandran V, Shanmugarajah S, Shen $\mathrm{H}$, Rosen $\mathrm{CF}$, et al. Association between environmental factors and onset of psoriatic arthritis in patients with psoriasis. Arthritis Care Res (Hoboken). 2011;63:1091-7.

23. Eder L, Shanmugarajah S, Thavaneswaran A, Chandran V, Rosen CF, Cook RJ, et al. The association between smoking and the development of psoriatic arthritis among psoriasis patients. Ann Rheum Dis. 2012;71:219-24.

24. Tsuruta N, Imafuku S, Narisawa Y. Hyperuricemia is an independent risk factor for psoriatic arthritis in psoriatic patients. J Dermatol. 2017;44:1349-52 (S. Imafuku, Department of Dermatology, Fukuoka University Faculty of Medicine, Fukuoka, Japan).

25. Li W, Han J, Qureshi AA. Smoking and risk of incident psoriatic arthritis in US women. Ann Rheum Dis. 2012;71:804-8. 
26. Nguyen U-SDT, Zhang Y, Lu N, Louie-Gao Q, Niu J, Ogdie A, et al. Smoking paradox in the development of psoriatic arthritis among patients with psoriasis: a population-based study. Ann Rheum Dis. 2018;77:119-23.

27. Thorarensen SM, Lu N, Ogdie A, Gelfand JM, Choi HK, Love TJ. Physical trauma recorded in primary care is associated with the onset of psoriatic arthritis among patients with psoriasis. Ann Rheum Dis. 2017;76:521-5.

28. Thumboo J, Uramoto K, Shbeeb MI, O'Fallon WM, Crowson CS, Gibson LE, et al. Risk factors for the development of psoriatic arthritis: a population based nested case control study. J Rheumatol. 2002;29:757-62.

29. Tey HL, Ee HL, Tan ASL, Theng TS, Wong SN, Khoo SW. Risk factors associated with having psoriatic arthritis in patients with cutaneous psoriasis. J Dermatol. 2010;37:426-30.

30. Muntyanu A, Abji F, Liang K, Pollock RA, Chandran V, Gladman DD. Differential gene and protein expression of chemokines and cytokines in synovial fluid of patients with arthritis. Arthritis Res Ther. 2016;18:296.

31. Abji F, Pollock RA, Liang K, Chandran V, Gladman DD. Brief report: CXCL10 is a possible biomarker for the development of psoriatic arthritis among patients with psoriasis. Arthritis Rheumatol (Hoboken, NJ). 2016;68:2911-6.

32. Julià A, Tortosa R, Hernanz JM, Cañete JD, Fonseca E, Ferrándiz C, et al. Risk variants for psoriasis vulgaris in a large case-control collection and association with clinical subphenotypes. Hum Mol Genet. 2012;21:4549-57.

33. Eder L, Chandran V, Pellett F, Pollock R, Shanmugarajah S, Rosen CF, et al. IL13 gene polymorphism is a marker for psoriatic arthritis among psoriasis patients. Ann Rheum Dis. 2011;70:1594-8.

34. Smolnikova M, Freidin M, Barilo A, Smirnova S. Analysis of association between cytokine gene polymorphisms and psoriatic disease in Russians of East Siberia. Meta Gene. 2018;19:60-4.

35. Duffin KC, Freeny IC, Schrodi SJ, Wong B, Feng B-J, Soltani-Arabshahi R, et al. Association between IL13 polymorphisms and psoriatic arthritis is modified by smoking. J Invest Dermatol. 2009;129:2777-83.
36. Savage L, Tinazzi I, Zabotti A, Laws PM, Wittmann M, McGonagle D. Defining pre-clinical psoriatic arthritis in an integrated dermato-rheumatology environment. J Clin Med Multidiscip. 2020;9:3262 (Digital Publishing Institute).

37. Acosta Felquer ML, LoGiudice L, Galimberti ML, Rosa J, Mazzuoccolo L, Soriano ER. Treating the skin with biologics in patients with psoriasis decreases the incidence of psoriatic arthritis. Ann Rheum Dis. 2021. https://doi.org/10.1136/ annrheumdis-2021-220865.

38. Gisondi P, Bellinato F, Targher G, Idolazzi L, Girolomoni G. Biological disease-modifying antirheumatic drugs may mitigate the risk of psoriatic arthritis in patients with chronic plaque psoriasis. Ann Rheum Dis. 2021. https://doi.org/10.1136/ annrheumdis-2021-219961.

39. Ash ZR, Tinazzi I, Gallego CC, Kwok C, Wilson C, Goodfield $\mathrm{M}$, et al. Psoriasis patients with nail disease have a greater magnitude of underlying systemic subclinical enthesopathy than those with normal nails. Ann Rheum Dis. 2012;71:553-6.

40. Savage L, Goodfield M, Horton L, Watad A, Hensor E, Emery P, et al. Regression of Peripheral Subclinical Enthesopathy in Therapy-Naive Patients Treated With Ustekinumab for Moderate-to-Severe Chronic Plaque Psoriasis: A Fifty-Two-Week, Prospective, Open-Label Feasibility Study. Arthritis Rheumatol (Hoboken, NJ). 2019;71:626-31 (D. McGonagle, Leeds Institute of Rheumatic and Musculoskeletal Medicine, University of Leeds, NIHR Leeds Biomedical Research Centre, Leeds Teaching Hospitals NHS Trust, Leeds, United Kingdom).

41. Kampylafka E, Simon D, d'Oliveira I, Linz C, Lerchen V, Englbrecht M, et al. Disease interception with interleukin-17 inhibition in high-risk psoriasis patients with subclinical joint inflammation-data from the prospective IVEPSA study. Arthritis Res Ther. 2019;21:178.

42. Taylor W, Gladman D, Helliwell P, Marchesoni A, Mease P, Mielants H, et al. Classification criteria for psoriatic arthritis: development of new criteria from a large international study. Arthritis Rheum. 2006;54:2665-73.

43. EULAR | ongoing initiatives [Internet]. https:// www.eular.org/ongoing_initiatives.cfm. Accessed 14 Sep 2021. 